Sustainability 2015, 7, 7086-7111; doi:10.3390/su7067086

OPEN ACCESS

sustainability

ISSN 2071-1050

www.mdpi.com/journal/sustainability

Article

\title{
The Bumpy Road toward Low-Energy Urban Mobility: Case Studies from Two UK Cities
}

\section{Tim Schwanen}

Transport Studies Unit, School of Geography and the Environment, University of Oxford, South Parks

Road, Oxford OX1 3QY, UK; E-Mail: tim.schwanen@ouce.ox.ac.uk; Tel.: +44-(0)-1865-285503

Academic Editors: Tan Yigitcanlar and Md. Kamruzzaman

Received: 1 April 2015 / Accepted: 26 May 2015 / Published: 2 June 2015

\begin{abstract}
Cities are increasingly seen as the places where innovations that can trigger a sociotechnical transition toward urban mobility are emerging and maturing. Processes such as peak car, rail renaissance and cycling boom manifest themselves particularly in cities, and success stories of cities experimenting with specific types of low-energy mobility abound in the academic literature. Nonetheless, innovation is known to be a precarious process requiring favorable circumstances. Using document analysis and in-depth interviews, this study examines the nature of low-energy innovation in the everyday mobility of people in two UK cities with favorable conditions for a transition away from fossil fuels - Brighton and Oxford. It shows that clear differences exist between the two cities in the sorts of innovation that emerge and diffuse as a result of path dependencies, local politics, and financial support from supra-local governments and agencies. While low-energy mobility currently has substantial momentum in both cities, the majority of low-carbon innovations in urban mobility are incremental rather than radical in nature, and their future is often imbued with uncertainty. The autonomy of small- and medium-sized cities as agents in bringing about transformational change toward low-energy urban mobility should not be overestimated.
\end{abstract}

Keywords: low-energy transport; carbon; energy consumption; sociotechnical transition; innovation; cities; United Kingdom 


\section{Introduction}

Current transport systems for people and freight are environmentally unsustainable [1-4]. In 2011, transport was responsible for $23 \%$ of global energy consumption [5] and $22 \%$ of $\mathrm{CO}_{2}$ emissions [6]. Both energy consumption and emissions continue to grow due to a range of mutually reinforcing factors and processes, including a near total—94\% [5]—reliance on oil; population growth; economic development; urban sprawl; the globalization of cultural ideas that tie car use and ownership to social progress, freedom and individuality; and governments' commitment to road building and investment in other infrastructures for carbon-intensive forms of mobility, such as maritime ports and airports [4,7].

Greenhouse gas (GHG) emissions from transport need to be reduced drastically, and the IPCC unambiguously calls for "aggressive and sustained" [4] (p. 602) measures yet also appreciates the monumentality of the challenges ahead: the growth of transport volumes in non-OECD countries and of intercontinental movements of people and goods risks cancelling out the benefits from technological advances and behavior change occurring across parts of Europe, North America and Australasia. In those regions, the growth of car use and ownership may have peaked $[8,9]$ and a rail renaissance, both within cities (metro, light rail) and between cities (high speed rail) [10-12], and cycling boom [13,14] can be witnessed. These developments seem to take place first and foremost in urban areas. Indeed, across the global North, cities lead the way in moving toward low-energy mobility-here used as shorthand for types of everyday mobility that consume less fossil fuels and emit smaller quantities of GHGs than do conventional internal combustion personal vehicles - for various reasons [15-17]: higher population densities make public transport, cycling and walking more practical and attractive compared to car use and ownership; populations are on balance relatively young, highly educated, environmentally conscious and willing to experiment with — or at least support — various forms of low-energy living; and governments are more likely to have the political, institutional and financial capacities to support low-energy mobility initiatives and experiments than are their suburban and rural counterparts.

Whilst encouraging, the currently observable gradual shifts across the global North are unlikely to be sufficient if transport's contribution to anthropogenic climate change is to be minimized. Across academics from various disciplinary backgrounds a consensus appears to be emerging around two key ideas. The first of these revolves around the need for systemic change, whereby prevailing systems of mobility-i.e., not only (vehicle) technologies, physical infrastructures and user practices, but also the cultural meanings associated with various forms of movement, markets, maintenance and repair, forms of regulation and policy making, and formal expertise about transport [18] — become durably reconfigured. The second is that such change can be triggered by the diffusion of one or more low-energy innovations - new technologies, institutional arrangements or user practices that differ to greater or lesser extent from prevailing mobility systems; examples include IT-supported mobility services (e.g., car/bike sharing), bio-fueled buses and smartcard-based integrated ticketing systems. In accordance with these views, a literature on innovations in transport is emerging [19,20], most of which is informed by the theoretical perspectives of strategic niche management (SNM) [21-23] and the multi-level perspective (MLP) [18,20,24,25], although a range of studies have also drawn on cultural approaches like practice theory [26-28] and the energy cultures framework [29,30].

The theoretical lens of SNM/MLP is particularly useful because of its comprehensive system orientation but also tends to privilege the temporal over the spatial dimensions of systemic change. 
Whilst offering useful conceptualizations of the moments at which innovations can break through and the temporalities involved in systemic change, it has less to say on where such processes will happen, why there, and which geographical circumstances will facilitate or complicate them (see also [31-39]). This can be considered a shortcoming given the urban character of the processes of peak car, rail renaissance and cycle boom across the global North.

The current paper seeks to contribute to a better understanding of the geographical dimensions of innovations in transport by focusing on the everyday mobility of people and adopting a comparative case study approach. It considers the UK cities of Brighton and Oxford as what Flyvbjerg [40] calls "critical cases" that enable conclusions which may also apply to other cities with less favorable conditions for systemic change. The UK is an appropriate setting because it was the first country to adopt legally binding $\mathrm{CO}_{2}$ emission reduction targets, which are linked to the 2008 Climate Change Act, and has allocated $£ 738.5 \mathrm{~m}$ to the Local Sustainable Transport Fund (2011-2016), which funds a program of locally designed and delivered policy packages aimed at stimulating sustainable forms of passenger transport [41]. Within this national context, Brighton and Oxford are two medium-sized cities with strong reputations in sustainable transport: bus usage is amongst the highest in the UK, and whilst Oxford is widely known as a city of cyclists, Brighton — used henceforth as synonym for the city's official name of Brighton and Hove - was among the first to adopt comprehensive cycling promotion policies in the UK. Both cities can be expected to be ahead of the curve in terms of transitioning to low-energy mobility systems and offer potentially fertile grounds for the emergence and flourishing of low-energy innovation in urban mobility. This makes these cities useful sites to examine which local processes and circumstances facilitate, complicate or obstruct systemic transitions toward low-energy urban mobility.

\section{Sociotechnical Transitions and Innovation}

Theoretically, the starting point for this paper is the multi-level perspective (MLP), which holds that systemic change requires processes at the sociotechnical landscape, regime and niche levels to somehow coincide and become interlinked [18,20,24,25]. A sociotechnical regime is a set of rules-cognitive routines, shared beliefs, social norms and conventions, regulations, industry standards, protocols, contracts, laws and so forth - that fulfill a societal function (e.g., everyday mobility) and thereby condition the practices through which the technology, infrastructure, markets, cultural values, user practices, maintenance and repair, regulation and formal knowledge that make up socio-technical systems are reproduced [18]. Innovation and experimentation occur within a regime but are normally incremental: they tend not to challenge the basic architecture of, and power relations undergirding, the rules associated with a prevailing sociotechnical system, but rather seek to minimize an existing system's negative externalities. In a transport context they are best exemplified by end-of-pipe innovations $[3,42]$, such as fuel economy improvements in internal combustion personal vehicles. Such innovations are typically led by incumbent regime actors.

In contrast, innovations in sociotechnical niches are more radical: they often involve new, non-incumbent actors and potentially challenge - or at least reconfigure - the rules of prevailing systems. This does not mean that regime actors are uninterested or uninvolved; they may participate to learn about new developments and future competition, but their commitment to a given niche's development may ultimately be restricted [43]. The sociotechnical landscape is to some extent a residual category [44]; it 
gathers all wider contexts and developments over which regime actors have little influence, from anthropogenic climate change to economic crises, demographic shifts and the rise of the Information Age, as well as the transition from welfare to workfare [45] according to which all adults in advanced liberal democracies should, in principle, be in paid employment (and which becomes easier if they can afford to own a private car). According to the MLP, landscape developments can put pressure on, and eventually destabilize, existing regimes, opening up opportunities for innovations in niches to diffuse and reconfigure regimes [25].

The number of studies using the MLP in a passenger transport context is increasing rapidly (e.g., [19,20,39,46-48]), although most focus on specific niches, such as electric vehicles [43,48,49]. Nonetheless, at least two studies have discussed a broader range of niches in contemporary passenger mobility. Based on research in the UK and Sweden, Nykvist and Whitmarsh [19] identify three types: radical vehicle technologies (e.g., battery and hybrid electric vehicles), mobility services (e.g., car/bike sharing, public transport) and mobility management programs seeking to reduce vehicular travel (e.g., promotion of active travel or substitution of physical travel by ICT-telecommuting, e-commerce, etcetera). Geels [20] has expanded this classification into six categories, two of which - green propulsion technologies and demand management - are closely aligned with Nykvist and Whitmarsh's radical vehicle technologies and mobility management, respectively. However, the other four categories refine and extend those by Nykvist and Whitmarsh:

- IT-based innovations not only encompass telecommuting programs and the like, but also intelligent transport systems seeking to increase transport's efficiency through real-time information provision and smartcard-based integrated ticketing;

- Public transport innovations, such as light rail systems, and improved information provision and ticketing systems;

- Intermodal travel programs that seek to integrate different systems such as car and bus travel (Park and Ride) or car and public transport with public bike sharing schemes; and

- Cultural and socio-spatial niches that challenge the normality of private car use through land use developments (e.g., compact cities, smart growth, Transit Oriented Development (TOD), Complete/Livable Streets and home zones), or collective/commercial ownership (car/bike sharing).

However useful these classifications of niches may be, they are complicated by three sets of issues. One is that regimes are non-singular in transport [20], especially in cities and more so in continental Europe than in the UK and certainly the USA, Canada and Australia. In many Danish, Dutch and German cities, for instance, there is now a decade-long tradition and sometimes dominance of the provision, regulation and consumption of multiple forms of transport deemed environmentally sustainable — rail, bus, also cycling — which complicate the distinction between regime and niche [13,15]. Many cycling-related, TOD or intermodal transport innovations cannot be considered radical in those cities, although they might be labeled as such in other geographical contexts [3]. Moreover, what counts as an incremental or radical innovation depends on how place-specific regimes interact with each other (see also [50]). In geographical contexts where mobility systems configured around car, public transport and cycling compete with each other - or are encouraged to do so because of wider, modally organized institutional set-ups - , publicly financed bike sharing and/or commercial car sharing schemes may be seen as radical innovations and often face an up-hill struggle to assert themselves. Yet, in places where multiple regimes 
are more symbiotic than competitive, publicly funded bike sharing and/or commercial car sharing schemes are more incremental innovations, enabled by incumbent actors seeking to exploit synergies.

Additionally, the dynamics of niche innovation cannot be reduced to merely replacing or reconfiguring one or more regimes because of their purportedly unsustainable character. Many niches are not only about creating and expanding social networks, creating shared expectations and visions, and collective learning about technologies or regulation, as much of the strategic niche management literature would have it [22]. They are often political, in one of two senses. Niche innovations can be grassroots innovations [51,52] or urban experiments [35] whose very point is to challenge the ways in which regime actors - and others closely aligned to them - go about addressing the climate change challenge. In the urban mobility context these innovations may be exemplified by community-led initiatives configured around shared cars [53] or focused on cycling. Niche innovations and experiments can also be politically in a strategic sense. This is because they are being framed and used by political and economic elites to enhance the global competitiveness of cities and city-regions in a (post)neoliberal world. This, for instance, was Hodson and Marvin's [31] interpretation of the attempts to create a hydrogen economy in London under Mayor Ken Livingstone in the 1990s and the subsequent demonstration projects with hydrogen-fueled buses.

Thirdly, there is a tendency in the recent transport-oriented literature to focus on specific niches and to do so in isolation from other innovations. As in the MLP literature more widely, the emphasis is often on new technologies, such as electric vehicles (EVs), or innovations in which new technologies play a significant role, such as most recent bike and car sharing schemes. Whilst the latter two can also be seen as socio-cultural innovations insofar as they promote a shift away from individual ownership, there has not been much attention for innovations in which technology plays a very limited role, such as walk/cycle-to-school initiatives or cycling cafes and hubs for cycling training, maintenance and/or storage. Such innovations can nonetheless be of critical importance to low-energy transitions, because they directly seek to reconfigure elements of sociotechnical systems other than technologies and transport infrastructures as conventionally understood, such as cultural values, user practices and maintenance and repair. As protagonists of cultural approaches [26-30] would rightfully argue, those innovations can play an important role in changing the meanings associated with particular ways of moving around the city, enhancing users' skills and confidence and ultimately normalizing low-energy mobility in the city. Moreover, most studies so far have looked at individual or at most several innovations rather than on larger numbers as Nykvist and Whitmarsh [19] and Geels [20] have done. This focus on single or at most several innovations is problematic insofar that innovations may reinforce one another (symbiosis) or rather out-compete each other, and such relations may be place-specific. Moreover, innovations may be "entwined becomings", meaning that one could not obtain its distinctiveness without the realization and evolution of others. Consider, for instance, a smartcard-based integrated ticketing system facilitating not merely the transfer between rail and bus, but also the storage of privately owned bikes at the train station of origin and the use of a shared car at the destination side to overcome the first and last mile challenges, respectively. Focusing on many initiatives and their interdependencies can thus offer a more systemic perspective on innovation in passenger mobility.

This paper addresses the above issues through an analysis of a large number and diverse range of innovations and their linkages in geographical contexts where multiple regimes - auto-, bus- and velomobility - compete, coexist and intermingle. It moves beyond classifications used previously $[19,20]$ 
to consider not only the geographical scale but also the involvement of specific types of actors and political entanglements. It also explores how the last two dimensions are critical to the mobilization of such resources as funding.

\section{Research Design}

\subsection{Innovations Defined}

Innovation is a polysemic and contested term: it means different things to different people in different circumstances (see also [54]). It must therefore be defined carefully, and here the term will be used to denote a new socio-technical configuration. This definition has several implications. For one, it means that an innovation is a combination of heterogeneous elements that link together and reach out across space and time. Those elements may include technical artifacts and infrastructures (e.g., the bikes, docking stations and GPS technologies in the case of recent bike sharing schemes), cultural values and norms, standards, regulations and forms of knowledge (e.g., pricing structures, subscription systems, such ideas as "cycling is healthy", the rules used to make decisions on the location of docking stations), as well as user practices. The novelty of an innovation lies in the fact that either existing elements are put together in a novel way, or that one or more of the elements are new. The words "new" and "novel" should be seen as relative and scale dependent. A distinction can be made between genuinely new (i.e., the first manifestation anywhere), and new in a particular bounded territory but possibly existing in a similar format or manner elsewhere. Borrowing from Upham and colleagues [55], we can call the former an original innovation and the latter a diffusion-based innovation. "New" is also relative to particular time scales. For passenger transport systems periods of 5-10 years seem to offer a reasonable time scale to consider something novel.

The above definition mean that at any point in time the number of innovations in urban mobility in a medium-sized city is potentially huge; any inventory or examination of innovations that can be expected to reduce energy consumption will be selective rather than exhaustive. Yet, this is not necessarily problematic, as long as those innovations that are likely to have the greatest impact on energy consumption are taken into consideration. These have been identified for the cities of Brighton and Oxford through an extensive analysis of existing documents and fieldwork (site visits, interviews). Attention has only been directed toward place-dependent low-energy innovations with a reasonable degree of organizational embedding in the territory associated with each city. Generic innovations that relate to the national scale - e.g., national government's attempts to subsidize the purchase of EVs or charging equipment by individuals or organizations throughout England and Wales, or peer-to-peer car rental schemes run exclusively at the national level — have been left out of consideration. It should also be appreciated that the focus is on innovations that can be expected to reduce GHG emissions and energy consumption per kilometer traveled; whether they do when in use is beyond the current study.

\subsection{Data and Analysis}

For both cities, data collection started with systematic and detailed internet searches for relevant policy documents, reports by transport providers (e.g., bus and car club operators) and other organizations (e.g., advocacy and community groups), information provided on websites, newspaper 
articles and blog posts. In this way information from many different types of stakeholders-incumbents, new actors and citizens - has been gathered. For both cities the focus of the search has been on materials since 2005; however, the majority of assembled documents relate to the period since 2010. This seems to reflect a combination of greater innovation activity in urban mobility, increased reporting on such innovations, and a greater inclination among organizations and (local) newspapers to make materials available online in recent years. The initial searches were conducted in the winter and summer of 2014 for Oxford and Brighton, respectively. The compiled archives have since been updated continually; at present (March 2015) 400+ documents are available for Oxford and 500+ for Brighton. Within the broader research project to which this paper belongs, a selection of the assembled documents has been subjected to in-depth textual analysis, although for this particular piece the emphasis has generally been on extracting information on the size and origins of financial budgets for particular initiatives.

The document analysis has been complemented by site visits by the author to experience specific innovations, and by in-depth interviews conducted by the author and/or co-workers. To date, 16 interviews have been conducted in Oxford and Brighton with mid-range and senior officials in local transport policymaking, local politicians, and representatives of bus/rail operators and community organizations. Interviews lasted between 30 minutes and two hours and were audio-recorded. Relevant parts have been transcribed and subjected to a largely inductive form of thematic interview analysis (cf. [56]).

\subsection{Comparative Case Study Approach}

This study adopts a case-study approach on the grounds that a specific city as case-if chosen carefully, and with appropriate caveats - can offer valuable insight in processes that exceed the city in question. This is especially so if a "critical case" with strategic importance in relation to a more general set of issues is examined [40]. However, this paper does not look at a single case-study but at two, which reflects its understanding of cities as "open, embedded and relational" [57] (p. 481). Cities are not sealed off, independent territorial units; they are articulations or nodes within wider - national and increasingly globalized - networks through which ideas, capital, objects and people circulate. Cities shape those circulations and are shaped by them; they are at once relational and territorial [58] as wider flows and dynamics are refracted through place-specific historically sedimented amalgams of social practices and customs, institutions and built environments, including transport infrastructures [59]. In this context considering two cities, rather than one, sensitizes us toward appreciating "interconnected trajectories [and] moves us away from searching for similarities and differences between two mutually exclusive contexts and instead toward relational comparisons that uses different cities to pose questions of one another" [57] (p. 480).

For Flyvbjerg [40] (p. 307) "no universal methodological principles exist by which one can with certainty identify a critical case". Hence, the decision to select Brighton and Oxford as case studies was based on what Bertilsson [60] calls an under-coded abduction. This is an "on trial" inference, or "the best, or the most economical at hand in order to solve [the] puzzle" [60] (p. 379) of identifying something - two critical cases - that can actually only be known through induction afterwards, once large numbers of materials have been assembled and scrutinized in a time-intensive process. In the current study the on trial inference was based on prior understanding of both cities': 
- Transport system - both cities are known to have very high levels of bus usage, in the UK only surpassed by London;

- Land use configuration - both are compact cities with significant planning constraints on expansion: Oxford is surrounded by a green belt, Brighton by the sea and nature reserves;

- Local economy - in both cities based on IT, knowledge intensive services, higher education, high tech manufacturing and tourism; and

- Population composition - large shares of highly educated young adults and professionals, often with progressive political beliefs (Brighton and Hove is the only local authority in the UK that in 2011-2015 had a local administration led by the Green Party), in combination with considerable pockets of social deprivation in South East Oxford and toward the east and north-east of Brighton's city center. Both sets of conditions depress car ownership and usage levels [61] and are conducive to bus travel and walking.

Nonetheless, there are also important differences between the two cities, of which three deserve particular mention. Brighton and Hove's population is almost twice as large, with 273,400 inhabitants against 150,200 in Oxford (2011 Census). Additionally, Brighton is a unitary authority with a single governmental organization-Brighton and Hove City Council (BHCC) - responsible for local transport planning, whereas local transport policy in Oxford involves both Oxfordshire County Council, which is the statutory regional transport authority, and Oxford City Council. This governmental complexity may influence local government support for innovations in urban mobility in Oxford. Finally, whilst Oxford has a long-standing reputation for high levels of cycling (within a UK context), Brighton's hilly topography is widely seen as making cycling less attractive. This is to some extent borne out by Table 1, although this also demonstrates that cycling for commuting has roughly doubled over the 2000s in Brighton.

Table 1. Modal split and increase in cycling for commuting (derived from $[62,63]$ ).

\begin{tabular}{cccc}
\hline & & Brighton and Hove & Oxford City \\
\hline & Car/van driver & $39.9 \%$ & $36.2 \%$ \\
& Car/van passenger & $3.9 \%$ & $3.5 \%$ \\
Modal split & Train & $11.3 \%$ & $2.7 \%$ \\
$(2011)$ & Bus & $15.2 \%$ & $17.8 \%$ \\
& Cycling & $5.4 \%$ & $19.1 \%$ \\
& Walking & $22.2 \%$ & $18.8 \%$ \\
\hline \multicolumn{2}{l}{ Increase in the number of people cycling to work (2001-2011) } & $2.1 \%$ & $2.0 \%$ \\
\hline
\end{tabular}

For ease of comparison the analysis below concentrates on low-energy innovations within the administrative boundaries of each city, the territories of BHCC and Oxford City Council.

\section{Innovations in Brighton and Oxford}

\subsection{Caveats}

In recent years place-dependent low-energy innovation activity with regard to the everyday mobility of people has been extensive in both Brighton and Oxford (Tables 2 and 3). It is even tempting to infer that both cities are transitioning toward reduced emissions and energy consumption in mobility. 
However, the information in Tables 2 and 3 is inevitably partial and in some ways indicative. That partiality follows from the fact that many small-scale and more or less informal initiatives by local community members (e.g., neighborhood/street-level peer-to-peer car sharing or awareness raising events, mobility management schemes by local employers) could not be included due to non-availability or paucity of information and documentation. Moreover, many minor innovations may well go unnoticed to the individuals involved, irrespective of their social role (community member, entrepreneur, policymaker, and so forth), and are therefore not documented in a publicly available format.

The contents of Tables 2 and 3 is indicative in regards to timing and budgets. As far as timings are concerned, it is usually very difficult to pinpoint the moment at which a particular innovation starts, so the emphasis in Tables 2 and 3 has been placed on the time at which initiatives became available for use, came in operation, or physical (re)construction took place. Information on available budgets in policy documents or press releases is often imprecise and based on a priori intentions; actual expenses can differ from that information in various ways. Budget overruns may occur, and based on the work of Flyvbjerg and colleagues $[64,65]$ — even if those authors' interest was in larger projects than those considered here-their possibility should not be discarded easily. Consider one example from Brighton. Press releases and reports in the local media habitually refer to $£ 850 \mathrm{k}$ or $£ 900 \mathrm{k}$ as the budget for Brighton Station's Cycle Hub, a building that has recently been erected next to the train station with Dutch-style cycling parking for 500 bikes, as well as a bike repair and cycle shop, a café, changing/shower facilities and a fitness facility. However, during one of the interviews it became clear that in reality the project would cost at least $£ 1.2 \mathrm{~m}$ because of various contingencies during the construction phase.

Moreover, information on the budgets for particular projects in policy documents or media reports often excludes a range of actual costs, such as the labor costs of involved personnel, money spent on preparatory research (e.g., feasibility studies), and the time needed to prepare bids to funding agencies. On top of this, information on actual expenses is often not publicly available. This makes it particularly difficult to gauge the budgets and costs of initiatives that are not led by local governments; among the latter BHCC tends to disclose more information on budgets than public authorities in Oxford. In light of these considerations, the budgets in Tables 2 and 3 have been reduced to six broad categories $-<£ 100 \mathrm{k}$, $£ 100 \mathrm{k}-<500 \mathrm{k}, £ 500 \mathrm{k}-<1 \mathrm{~m}, £ 1 \mathrm{~m}-<3 \mathrm{~m}, £ 3 \mathrm{~m}-<10 \mathrm{~m}$, and $>£ 10 \mathrm{~m}$ (without correction for inflation) — and should be seen as conservative estimates of actual expenses. Still, a focus on budgets is potentially more revealing of stakeholders' priorities and orientations than the rhetoric that is sometimes used in policy documents, press releases, brochures and the like.

\subsection{General Observations}

Apart from pointing toward extensive innovation activity in recent years in both cities, the materials on which Tables 2 and 3 have been based highlight the usefulness of thinking about innovations as ensembles of new and old elements (Section 3.1). Consider as an example Oxonbike, the public bike sharing scheme that Oxfordshire County Council has set up for commuters in East Oxford with financial support from the Local Sustainable Transport Fund (LSTF). The novelty of this scheme does most certainly not lie in the idea of sharing bikes, thinking about mobility as a service, or its framing as enhancing Oxford's competitiveness in a globalizing economy; numerous schemes in other cities in the UK, and indeed across the world, had long since exhausted the originality of this set-up by 2010 . This 
scheme is innovative in its symbiotic links to other innovations seeking to reduce car use in East Oxford, such as the expansion of the Thornhill Park and Ride (P\&R) site on the eastern fringe of the city, the improvement to the bus lane and services connecting Thornhill with key employment sites in East Oxford and the city center, and mobility management initiatives encouraging employees to change their commuting behavior. This, then, is a clear example of an incremental innovation with the involved actors exploiting synergies between regimes.

Oxonbike also highlights the relativity of innovations. New to Oxford and decidedly different from the completely commercial Brompton bike hire scheme that offers folding bikes to subscribers at the city's train station, it is a singular innovation yet also exemplary of the diffusion of an ensemble of elements tried and implemented (with varying levels of success) in numerous other cities across Europe, North America, Australasia, and increasingly in the global South. The Oxonbike example thus allows a second general observation to be made: the vast majority of innovations are diffusion-based rather than genuinely new (Section 3.1). The EV charging points, railway station design, information provision through signage posts to assist pedestrian way finding, smart ticketing for bus travel, and internet-based journey planners provide only part of the evidence to substantiate this claim. Even the aforementioned Cycle Hub at Brighton Station bears clear resemblance to the Cycling Point at Leeds Station, which opened in 2010, was also developed by a consortium of stakeholders led by a train operating company (Abellio in Leeds, Southern in Brighton) and was itself inspired by similar developments at city-center railway stations in the Netherlands. This is one reason why cities have to be conceptualized as open, embedded and relational [48]. Initiatives move between locations; while they are new to $a$, this observation is relativized once $b, c, \ldots$ are brought into the frame. And yet, as the geographical literature on innovation diffusion [66,67] and more recently policy mobilities [68-70] has suggested, diffusion - and particularly effective diffusion — entails adaptation and hence novelty; it is rare that something works if it is simply transplanted from site $x$ to $y$. So, whilst Upham et al.'s [55] distinction of original versus diffusion-based innovations is useful, this cannot be seen as absolute but should be considered in terms of degrees of originality or "diffusionness" (given a particular spatial and temporal scale).

Seen thus, there are some innovations in Tables 2 and 3 that qualify as relatively original, at least in the UK context. The retrofitting of Brighton's Lewes Road - the main connection between Brighton's city center and the city's two universities (Sussex, Brighton), its football stadium and the suburb of Lewes - provides useful examples because of its floating bus stops and the construction of a bus lane to separate a segregated cycle path from car travel. The idea of the latter is that the bus lane offers additional protection to cyclists because it is used much less intensely than the car lane. Regarding the floating bus stops, which are commonly observed in parts of continental Europe, a senior transport planner highlighted the originality of the design and the learning processes involved: "it's one of the first times it's been tried in the UK, we spent quite a bit of time working out how that would actually work here. It's not proven design and there was nothing you pull out of the guidance, the technical guidance saying this is how you should do that. So there had to be a slight willingness [among policymakers] for designers to go out on a bit of a limb". 
Table 2. Selected place-dependent low-energy innovations in urban mobility, Brighton.

\begin{tabular}{|c|c|c|c|c|c|}
\hline Category & Innovation & When & Spatial scope & Lead actor(s) & Budget and main source(s) \\
\hline \multirow{5}{*}{$\begin{array}{c}\text { Green } \\
\text { propulsion } \\
(c f .[20])\end{array}$} & Biofueled bus services & 2007 & Region & nfp bus operator & Unknown-savings, shares, revenue \\
\hline & EV charging infrastructure & $2009 / 10$ & City & LG, fp operator & $£ 500 \mathrm{k}-<1 \mathrm{~m}-\mathrm{LG}, \mathrm{CA}$ \\
\hline & Euro 5 compliant int. combustion buses & 2011 & Region & fp bus operator & $>£ 10 \mathrm{~m}-$ bus operators \\
\hline & E-bike demonstration project & $2011 / 14$ & Neighborhood & University, LG & $£ 1 \mathrm{~m}-<3 \mathrm{~m}-$ LSTF, research councils \\
\hline & HEV buses & $2012 / 13$ & Region & fp bus operator & $£ 1 \mathrm{~m}-<3 \mathrm{~m}-\mathrm{NG}, \mathrm{fp}$ bus operator \\
\hline \multirow{4}{*}{$\begin{array}{l}\text { Intermodal } \\
\text { transport } \\
(c f .[20])\end{array}$} & Bus service at railway station & $2011 / 14$ & Site, Axis & LG, fp bus operator & $£ 500 \mathrm{k}-<1 \mathrm{~m}-\mathrm{LSTF}$ \\
\hline & Railway station redesign & $2012 / 13$ & Site & LG, NR & $£ 3 \mathrm{~m}-<10 \mathrm{~m}-\mathrm{NG}, \mathrm{NR}, \mathrm{LSTF}$ \\
\hline & Integrated ticketing bus and car club & 2013 & City & fp operators & Unknown—fp operators \\
\hline & Cycle Hub, Brighton railway station & $2014 / 15$ & $\begin{array}{l}\text { Site (facility), City } \\
\text { (catchment area) }\end{array}$ & Train operator, NR, LG & $£ 1 \mathrm{~m}-<3 \mathrm{~m}-\mathrm{NG}, \mathrm{LG}, \mathrm{NR}$, train operator \\
\hline \multirow{6}{*}{$\begin{array}{c}\text { Public } \\
\text { transport } \\
(c f .[20])\end{array}$} & Talking bus stops for vis. impaired & 2007 & City & LG, fp bus operator & Unknown—fp bus operator \\
\hline & Real time information at bus stops & 2009 & Region & LG, bus operators & $£ 1 \mathrm{~m}-<3 \mathrm{~m}-\mathrm{LSTF}$, bus operators \\
\hline & $\begin{array}{l}\text { Eco-driving technology and training for } \\
\text { bus drivers }\end{array}$ & 2009 & Region & fp bus operator & Unknown-fp bus operator \\
\hline & Smartcard ticketing buses & 2011 & Region & fp bus operator & Unknown—fp bus operator \\
\hline & Bus stop improvement & $2012 / 13$ & City & LG, fp bus operator & $£ 1 \mathrm{~m}-<3 \mathrm{~m}-\mathrm{LSTF}$ \\
\hline & Bus ticketing on smartphone & 2013 & Region & fp bus operator & Unknown-bus operator \\
\hline \multirow{3}{*}{$\begin{array}{l}\text { Mobility } \\
\text { services } \\
(c f .[19])\end{array}$} & City Car Club & 2003 & Neighborhood/City & fp operator & Unknown-fp operator \\
\hline & Streetcar/Zipcar & $2005^{\ddagger}$ & Neighborhood/City & fp operator & Unknown-fp operator \\
\hline & Car clubs to low-income areas & 2009 & Neighborhood & LG & $<£ 100 \mathrm{k}-\mathrm{EU}$ \\
\hline \multirow{3}{*}{$\begin{array}{c}\text { Mobility } \\
\text { management } \\
\text { and support } \\
(c f .[19])\end{array}$} & Cycling training at schools & 2005 & City & LG, Sustrans & $£ 500 \mathrm{k}-<1 \mathrm{~m}-\mathrm{NG}, \mathrm{CDT}, \mathrm{CT}, \mathrm{LG}$, Sustrans \\
\hline & Cycling awareness events & 2005 & City & LG, CO’s & $£ 500 \mathrm{k}-<1 \mathrm{~m}-\mathrm{CDT}, \mathrm{CT}, \mathrm{LG}$ \\
\hline & Travel planning, door-to-door & 2006 & City & LG & $£ 3 \mathrm{~m}-<10 \mathrm{~m}-\mathrm{CDT}, \mathrm{CT}, \mathrm{LSTF}, \mathrm{EU}, \mathrm{LG}$ \\
\hline
\end{tabular}


Table 2. Cont.

\begin{tabular}{|c|c|c|c|c|c|}
\hline Category & Innovation & When & Spatial scope & Lead actor(s) & Budget and main source(s) \\
\hline \multirow{5}{*}{$\begin{array}{c}\text { Mobility } \\
\text { management } \\
\text { and support } \\
(c f .[19])\end{array}$} & $\begin{array}{l}\text { Travel planning at schools, } \\
\text { universities and employers }\end{array}$ & 2006 & City & LG & $£ 500 \mathrm{k}-<1 \mathrm{~m}-\mathrm{CDT}, \mathrm{CT}, \mathrm{NG}, \mathrm{EU}$, Sustrans \\
\hline & Internet-based journey planner & 2007 & City & LG & $£ 100 \mathrm{k}-<500 \mathrm{k}-\mathrm{LG}, \mathrm{EU}, \mathrm{LSTF}$ \\
\hline & Bike-Off cycle security project & $2008 / 10$ & City & LG & $<£ 100 \mathrm{k}-\mathrm{EU}, \mathrm{LG}$ \\
\hline & Pedestrian way finding info & $2011 / 14$ & City center, Axes & LG & $£ 500 \mathrm{k}-<1 \mathrm{~m}-\mathrm{LSTF}, \mathrm{LG}$ \\
\hline & $\begin{array}{l}\text { Circus Street Bike Hub, incl. bike } \\
\text { maintenance and cycling training }\end{array}$ & 2014 & $\begin{array}{l}\text { Site (facility), City } \\
\text { (catchment area) }\end{array}$ & $\mathrm{CO}, \mathrm{LG}$ & $<£ 100 \mathrm{k}-\mathrm{LSTF}$, loans $\&$ revenues \\
\hline \multirow{7}{*}{$\begin{array}{l}\text { Physical } \\
\text { infrastructure } \\
\text { retrofit }\end{array}$} & Cycling retrofit Grand Avenue/Drive & $2005 / 08$ & Axis & LG & $£ 500 \mathrm{k}-<1 \mathrm{~m}-\mathrm{CDT}$ \\
\hline & Cycling retrofit Old Shoreham Rd & 2012 & Axis & LG & $£ 500 \mathrm{k}-<1 \mathrm{~m}$-Sustrans, NG, LG \\
\hline & $\begin{array}{l}\text { Minor cycling retrofits } \\
\text { (e.g., ASLs, priority and signage) }\end{array}$ & $\begin{array}{c}2005 \\
\text { onwards }\end{array}$ & City & LG & $£ 500 \mathrm{k}-<1 \mathrm{~m}-\mathrm{CDT}, \mathrm{CT}, \mathrm{EU}, \mathrm{LG}$ \\
\hline & $\begin{array}{l}\text { Cycling retrofit other thoroughfares } \\
\text { and cycling links/roads }\end{array}$ & $\begin{array}{c}2008 \\
\text { onwards }\end{array}$ & Axes & LG & $£ 3 \mathrm{~m}-<10 \mathrm{~m}-\mathrm{LG}, \mathrm{NG}, \mathrm{CT}, \mathrm{EU}, \mathrm{LSTF}$ \\
\hline & Cycling parking & $\begin{array}{c}2009 \\
\text { onwards }\end{array}$ & City & LG & $£ 100 \mathrm{k}-<500 \mathrm{k}-\mathrm{CT}, \mathrm{EU}, \mathrm{LG}$, train operator \\
\hline & Redesign Seven Dials roundabout & 2012 & Site & LG & $£ 100 \mathrm{k}-<500 \mathrm{k}-\mathrm{NG}, \mathrm{LG}$ \\
\hline & Cycle/bus retrofit Lewes Road & $12 / 14$ & Axis & LG & $£ 1 \mathrm{~m}-<10 \mathrm{~m}-\mathrm{LSTF}$ \\
\hline \multirow{4}{*}{ Other } & $\begin{array}{l}\text { Cycling monitoring } \\
\text { (incl. interactive cycling counter) }\end{array}$ & 2005 & City & LG & $£ 100 \mathrm{k}-<500 \mathrm{k}-\mathrm{CDT}, \mathrm{CT}, \mathrm{EU}, \mathrm{LSTF}, \mathrm{LG}$ \\
\hline & Smart traffic signaling & $2011 / 14$ & Axis & LG & $£ 500 \mathrm{k}-<1 \mathrm{~m}-\mathrm{LSTF}$ \\
\hline & 20mph speed limit & $2012 / 14$ & City & LG & -- \\
\hline & Controlled parking zones & 2012 & City & $\mathrm{LG}$ & -- \\
\hline
\end{tabular}

Notes: Axis = covers a transport a specific road; C(D)T = Cycling (Demonstration) Town grant; City = coverage (most of) the city; City center = covers city center only; $\mathrm{CO}=$ community organization; EU = EU CiViTAS grant; (n)fp = (not) for profit; LG = local government; LSTF = Local Sustainable Transport Fund grant; Neighborhood = covers a specific neighborhood outside the city center; $\mathrm{NG}=$ national government; $\mathrm{NR}=$ Network Rail; Region = exceeds city to cover (most of) the urban region; Site $=$ restricted to a single location; ${ }^{\ddagger}$ Stopped operations in Brighton in early $2010 \mathrm{~s}$. 
Table 3. Selected place-dependent low-energy innovations in urban mobility, Oxford.

\begin{tabular}{|c|c|c|c|c|c|}
\hline Category & $\begin{array}{c}\text { Innovation } \\
\end{array}$ & When & Spatial scope & Lead actor(s) & Budget and main source(s) \\
\hline \multirow{5}{*}{$\begin{array}{c}\text { Green } \\
\text { propulsion } \\
(c f .[20])\end{array}$} & EV charging infrastructure & 2009 onwards & City & LG, operator & $£ 1 \mathrm{~m}-<3 \mathrm{~m}-\mathrm{LG}, \mathrm{NG}$ \\
\hline & Mini E field trial & $2009 / 11$ & City & CM, university, LG & $£ 5 \mathrm{~m}-<10 \mathrm{~m}-\mathrm{CM}, \mathrm{NG}$ \\
\hline & Euro 5 compliant int. comb. buses & 2009 & Region & Bus operators & $£ 5 \mathrm{~m}-<10 \mathrm{~m}-$ bus operators \\
\hline & HEV buses & $2009 / 13$ & Region & Bus operators, LG & $>£ 10 \mathrm{~m}-\mathrm{NG}$, bus operators \\
\hline & Retrofit buses to Euro 5 standard & 2012 & City centre & Bus operators & $£ 500 \mathrm{k}-<1 \mathrm{~m}-$ bus operators, NG \\
\hline \multirow{3}{*}{$\begin{array}{l}\text { Intermodal } \\
\text { transport } \\
(c f .[20])\end{array}$} & Thornhill P\&R intelligent access & 2012 & Site & $\mathrm{LG}$ & $<£ 100 \mathrm{k}-\mathrm{LSTF}$ \\
\hline & Thornhill P\&R expansion & $2013 / 14$ & $\begin{array}{c}\text { Site (facility), } \\
\text { Region (catchment) }\end{array}$ & LG & $£ 1 \mathrm{~m}-<3 \mathrm{~m}-\mathrm{LSTF}$ \\
\hline & Railway station redesign & 2014 & Site & NR, LG, train operators & $>£ 10 \mathrm{~m}-\mathrm{NG}, \mathrm{LG}$, rail sector \\
\hline \multirow{5}{*}{$\begin{array}{c}\text { Public } \\
\text { transport } \\
(c f .[20])\end{array}$} & $\begin{array}{l}\text { Eco-driving technology and } \\
\text { training for bus drivers }\end{array}$ & 2008 & Region & bus operator & $£ 100 \mathrm{k}-<500 \mathrm{k}-\mathrm{fp}$ bus operator \\
\hline & RTI at bus stops & $2009 / 14$ & City & LG, bus operators & $£ 100 \mathrm{k}-<500 \mathrm{k}-\mathrm{LSTF}$, bus operators \\
\hline & $\begin{array}{l}\text { East West rail (Oxford, Bedford), } \\
\text { incl. new station Oxford Parkway }\end{array}$ & 2011 & Region & NR, train operators, LG & $>£ 10 \mathrm{~m}-\mathrm{NG}, \mathrm{LG}$, rail sector \\
\hline & Smartcard ticketing buses & 2011 & Region & Bus operators, LG & Unknown—-bus operators, LSTF \\
\hline & New bus services Headington-city & 2013 & City & LG, bus operator & $£ 1 \mathrm{~m}-<3 \mathrm{~m}-$ LSTF, bus operator \\
\hline \multirow{7}{*}{$\begin{array}{l}\text { Mobility } \\
\text { services } \\
(c f .[19])\end{array}$} & Streetcar/zipcar & Mid-2000s & Neighborhood/City & fp operator & Unknown-fp operator \\
\hline & Co-wheels/ Commonwheels & Mid-2000s & Neighborhood/City & fp operator & Unknown-fp operator \\
\hline & Oxford Liftshare & 2009 & Region & LG, fp company & $<£ 100 \mathrm{k}$ (start)-LG \\
\hline & Oxford Brookes Uni car club & 2013 & Neighborhood & University, fp operator & Unknown-university \\
\hline & North Oxford e-car club & 2013 & Neighborhood & $\mathrm{CO}, \mathrm{nfp}$ operator & Unknown- $-\mathrm{CO}$ \\
\hline & Brompton bike share & 2013 & Site & fp operator & Unknown - fp operator \\
\hline & Oxonbike bike share & 2013,2014 & Neighborhoods & LG, fp operator & $£ 100 \mathrm{k}-<500 \mathrm{k}-\mathrm{LSTF}$ \\
\hline
\end{tabular}


Table 3. Cont.

\begin{tabular}{|c|c|c|c|c|c|}
\hline Category & Innovation & When & Spatial scope & Lead actor(s) & Budget and main source(s) \\
\hline \multirow{4}{*}{$\begin{array}{c}\text { Mobility } \\
\text { management } \\
\text { and support } \\
\text { (cf. [19]) }\end{array}$} & Travel hub and easitOxford travel information & 2011 & City & LG & $£ 100 \mathrm{k}-<500 \mathrm{k}-\mathrm{LSTF}$ \\
\hline & Pedestrian way finding info city center & $2011 / 12$ & City center & LG & Unknown-LG \\
\hline & Internet-based journey planner & 2012 & Region & LG & $<£ 100 \mathrm{k}-\mathrm{LSTF}, \mathrm{LG}$ \\
\hline & $\begin{array}{l}\text { Broken Spoke bike maintenance, cycling } \\
\text { training }\end{array}$ & 2012 & $\begin{array}{l}\text { Site (facility), City } \\
\text { (catchment area) }\end{array}$ & $\mathrm{CO}$ & $<£ 100 \mathrm{k}-\mathrm{CO}, \mathrm{LG}$ \\
\hline \multirow{4}{*}{$\begin{array}{c}\text { Physical } \\
\text { infrastructure } \\
\text { retrofit }\end{array}$} & Various cycling paths/routes & 2010 & Axes & LG & $£ 100 \mathrm{k}-<500 \mathrm{k}-\mathrm{LG}, \mathrm{LSTF}$ \\
\hline & Plains roundabout retrofit & $2014 / 15$ & Site & LG & $£ 1 \mathrm{~m}-<3 \mathrm{~m}-\mathrm{NG}, \mathrm{LG}$ \\
\hline & Bus retrofit/bus lane London $\mathrm{Rd}$ & $2014 / 15$ & Axis & LG & $£ 500 \mathrm{k}-<1 \mathrm{~m}-\mathrm{LSTF}$ \\
\hline & Shared space retrofit Frideswide Square & 2015 & Site & LG & $£ 3 \mathrm{~m}-<10 \mathrm{~m}-\mathrm{LG}$ \\
\hline Other & Low emission zone, city center & 2014 & City center & LG, bus operators & -- \\
\hline
\end{tabular}

Notes: Axis = covers a transport a specific road; City = coverage (most of) the city; City center = covers city center only; CM = car manufacturer; CO = community organization; Neighborhood = covers a specific neighborhood outside the city center; $(\mathrm{n}) \mathrm{fp}=($ not $)$ for profit; LG = local government; LSTF = Local Sustainable Transport Fund; NG = national government; NR = Network Rail; Region = exceeds city to cover (most of) the urban region; Site = restricted to a single location. 
A third observation relates to the difficulty of straightforwardly applying Nykvist and Whitmarsh's [19] and Geels's [20] classifications of niche innovations to the cities of Brighton and Oxford. The categories those authors propose overlap quite strongly. For instance, the IT-based category that Geels distinguishes is closely interwoven with those for public transport, mobility management and mobility services. Once those are discounted, there is little that remains other than a residual smart traffic signaling initiative in Brighton (classified as "Other" in Table 3). Geels's [20] public transport category could also have been merged with others, but has been retained because both cities have a well developed busmobility regime with (local) bus companies as powerful players capable of developing unique innovations that are unirather than intermodal in the sense of only seeking to make bus more attractive to potential users. His category of cultural and socio-spatial niches has been traded for Nykvist and Whitmarsh's [19] more specific class of mobility services, and their mobility management category has been expanded slightly to also encompass forms of support, such as cycle training and maintenance facilities. Moreover, both Nykvist and Whitmarsh [19] and Geels [20] seem to under-appreciate the significance of retrofits to existing physical infrastructure (see below for discussion on their status as niche) in attempts to transition toward a more cycling oriented urban mobility system. Physical infrastructure retrofits have therefore been added as a separate category.

A further conclusion to be drawn from Tables 2 and 3 is the dominance of incumbent actors. These include first and foremost local governments, but also the Department for Transport (DfT) at the national level; bus companies that have served Brighton and Oxford for decades and more; and key actors in the rail sector, such as Network Rail-the organization that manages and looks after rail tracks and associated infrastructure as well as many stations on behalf of national government — and well-established train operating companies such as Southern (Brighton) and Chiltern Railways (Oxford). The question can be raised whether this dominance is problematic, and the answer is not immediately obvious. However, as Raven [71] (p. 2392) suggests, dominance of incumbents can enhance entry barriers for new actors with alternative views and practices and result in the "[d]anger of getting stuck into [the] existing regime without radical transformation". This is potentially a significant issue in relation to urban mobility, not least because incumbent transport service providers in UK cities are often focused on a single mode - the one they provide — and, despite significant and ongoing changes in orientation and practice, are conditioned by routines accumulated over decades to a greater extent than new actors tend to be.

The dominance of incumbents can be explained with reference to two sets of factors. One is that urban transport is a tightly regulated domain of society, at least in advanced liberal democracies like the UK. Local government, and because of the UK state's strongly centralized character in regard to transport despite 15 years of devolution [72] also the DfT, holds strong power over urban mobility initiatives. In both Brighton and Oxford these manifest themselves in at least three roles for local government:

- Regulator - for instance, being formally in charge of road/street space they play a pivotal role in the allocation of parking bays to all forms of car club, and by having a decisive say in the granting of franchises to bus operators, they have considerable influence over the practices of the latter. They also provide permits for many grassroots initiatives to provide and raise awareness about low-energy forms of urban mobility; 
- Financier - they support many innovations by both private sector and community organizations with grants. Even grassroots innovations with socially and politically progressive identities, such as Oxford's Broken Spoke bike cooperative and the Circus Street cycle hub in Brighton, are to some extent dependent on small-scale financial support from local government. Financial support can also come in the form of officer time, as exemplified by the time council staff spent on the preparation of bids to DfT funding streams to subsidize the purchase of hybrid electric vehicles (HEV) by the main bus operators in Oxford and Brighton; and

- Initiator - they develop, lead, coordinate and are ultimately responsible for many of the innovations listed in Tables 2 and 3. This reflects both the changing configurations of finance in English transport planning (see below), and the enthusiasm and determination of many policy makers - at all levels of organizational hierarchy - and some local politicians in encouraging a transition toward low-energy urban mobility systems.

The other explanation is related to the first: incumbent actors, such as long-standing bus and train operators and local government, are capable of commanding financial resources for investments in innovations that new actors in the realm of low-energy mobility-community organizations, start-up companies, universities, and so forth - cannot access. As already implied, a very large share of those financial resources comes from national government but also important is capital within incumbent firms, such as Brighton and Hove Bus Company (BHBC) and Oxford Bus Company (OBC). Both these firms are part of the Go-Ahead Group, a national conglomerate of formerly independent local/regional public transport companies, and their membership has facilitated investment in HEV buses in multiple ways. The capacity to command funding is particularly important in the transport sector, where a long-standing culture prevails of addressing perceived problems through techno-fixes and interventions in the physical infrastructures that enable particular forms of transport.

The above discussions also have ramifications for the literature on transitions and innovations discussed in Section 2. There are clear examples of grassroots innovations that explicitly challenge regime actors' ways of reducing GHG emissions from urban mobility; Broken Spoke and the Circus Street Bike Hub have already been mentioned and other examples are North Oxford's e-car club and The Big Lemon, a small social enterprise in Brighton that operates buses and coaches running on bio-fuel based on cooking oil collected from restaurants around the region. Nonetheless, and notwithstanding the earlier caveat about the partiality of Tables 2 and 3, it seems that even in the progressive cities of Brighton and Oxford such grassroots innovations play a fairly limited role within innovation activity at the city level. They are critically important in servicing specific user groups whose mobility needs are not adequately catered for by incumbents and in offering paid/voluntary work to specific individuals who might otherwise struggle in a neoliberal labor market, but they tend to be marginal — and in some ways marginalized - actors within transition trajectories in urban mobility in the two cities studied here.

Indeed, the more strategic sense in which low-energy innovations are political seems to be more significant, particularly in Oxford and especially in recent years. Funding is again important here: under the Conservatives-dominated Coalition Government of David Cameron funding streams from national to local levels have increasingly been reframed and repurposed. Local initiatives seeking to reduce emissions and energy consumption in urban mobility have to make a clearly identifiable - i.e., with conventional transport appraisal methods quantifiable — contribution to economic growth and city-regions' 
competitiveness in the global marketplace. This even applies to the LSTF and has played a significant part in DfT's decision-making about which local governments to allocate funding.

\subsection{Geographies of "Radicalness"}

The general observations above also raise questions about the usefulness of the regime/niche distinction in relation to urban mobility in Brighton and Oxford. Given the dominance of incumbent actors in initiating, coordinating and funding low-energy innovations, dualistic opposition-regime versus niche - is to be avoided; differences are at best gradual. There are only degrees of "radicalness" of innovations in terms of differences vis-à-vis existing regimes in both a technological and a social sense, and those degrees are geographically differentiated. Three examples can clarify this point.

Firstly, car clubs - the English term for formal car sharing schemes operated by a for-profit company (e.g., City Car Club and the North-American company Zipcar which took over UK-based Streetcar in 2010) or a not-for-profit organization (e.g., e-car club which runs the North Oxford community scheme that at the moment of writing was still organized around a single car) - are much better integrated into the regimes of auto- and busmobility in Brighton than in Oxford. This is partly a scale issue: according to City Car Club (CCC), the sole commercial operator in Brighton in 2014, that city has the largest use of car clubs in South East England outside London. Indeed, Oxford's 36 cars across four operators in mid-2014 are clearly outnumbered by CCC's 100+ vehicles, which are also more differentiated in terms of size and type than Oxford's and distributed over more than 60 pick-up locations in Brighton. This is one reason why BHBC collaborate with the car club and bus card holders enjoy a reduced first-year subscription rate to CCC (Table 2). Yet, political support is also important: Brighton's minority Green administration has actively promoted Brighton's car club and in some documents prides itself as championing car sharing (even if some policymakers' support is more ambiguous, in part because CCC was one of several car clubs that were reluctant to get involved in an EU-funded attempt by policymakers to extend car sharing to some of the city's more deprived areas). An important consequence of the Greens' actions has been to facilitate the emergence of symbiosis between auto- and busmobility in Brighton. This stands in sharp contrast to Oxford where car sharing has received much less active support from politicians and policymakers, and relationships with the bus sector are non-symbiotic. Car sharing innovations are more radical in the sense of differing more strongly from prevailing regimes in Oxford than in Brighton.

Secondly, juxtaposing Tables 2 and 3 demonstrates considerably greater investment in HEV buses by bus companies in Oxford than in Brighton. At the same time, BHBC has invested much more in Euro 5 standard compliant (i.e., emitting no more than 2.0 grams of $\mathrm{NO}_{\mathrm{x}}$ per kilowatt hour of engine power) buses than OBC, its Oxford sister-company with a smaller bus fleet. This difference is to some extent linked to Oxford City Council's air quality strategy and the collaboration of county and city councils with all bus companies serving the city center in order to create a Low Emission Zone (LEZ). Effective since January 2014, the LEZ concentrates on $\mathrm{NO}_{\mathrm{x}}$ levels but still has important GHG emission reduction co-benefits. In Oxford and beyond, the LEZ is seen as a concrete success in tackling long-standing problems with poor air quality. It is one of the first in the UK outside London and stipulates that buses should be at least Euro 5 compliant (although there are many exceptions watering down what at first glance appears

to be a very solid measure). However, by ordering many HEV buses, OBC has gone beyond what has 
been required, which seems to reflect both its wider philosophy - it positions itself "one of the greenest bus companies in the UK" ([73], no pagination) - and anticipation of more ambitious plans by the city to create a zero-emission zone in several years. As they have been embraced more fully and at an earlier point in time in Oxford, HEV bus technologies are more radical in Brighton (albeit considerably less radical than those of The Big Lemon, which is also socially radical because it is a social enterprise that is more deeply committed to environmental and social sustainability). All in all, green propulsion technologies are more radical in the Brighton than the Oxford context.

Finally, there are differences in the position of cycling. Not only has cycling long since been more common in Oxford; that city has also had for some time now a subaltern regime [20] of velomobility characterized, amongst others, by dedicated physical infrastructure along many of the city's main roads, a substantial number of bike shops, local government offering cycling training in primary schools, support for cycling by two universities and - in the UK context — high usage levels among the general public. This regime has certainly expanded and gained in complexity and texture over the past decade, but the situation in Oxford is quite different from that in Brighton. There the local government has been very proactive in trying to create a cycling regime, partly in response to autonomous developments within the local community but also because of strong support from some local politicians, especially from the Green Party (although cycling continues to be a subject of political contention in Brighton). Since 2005, local government has concentrated on two sets of initiatives that can, following convention in transport studies [74,75], be classified as:

- "Soft" - cycling training in schools and more recently also the city's two universities, as well as travel planning for households, employers and businesses; and

- "Hard" - the creation of a network of retrofitted major thoroughfares, including Lewes Road, as well as the provision of bike racks and other minor interventions in the materiality of public spaces to make cycling more convenient. The idea has been, in the words of one senior transport planner, to create the quality of infrastructure "so you don't have to be a kind of hardcore cyclist, it's designed for all levels of ability".

It has taken about a decade to realize and implement these initiatives and activity is still ongoing. As innovations, they were never very radical — not least because of the strong support and involvement of local policymakers - but over the past ten years they have been "mainstreamed" and become increasingly incremental. As a subaltern regime of velomobility started to emerge within Brighton, more recent innovations lost the greater degrees of radicalness characterizing earlier initiatives (even if they can still be considered radical relative to the national scale, as the earlier discussion of Lewes Road suggests).

\subsection{Further Geographical Differentiations}

There are three other geographical variations at the city level that merit attention further to the place-specificity of what constitutes a radical innovation. One relates to subtle differences in the geographical scope of innovations (Tables 2 and 3). Partly as a result of the greater expansion of car clubs and emphasis on cycling-related interventions in Brighton, mobility services are more localized in Oxford and there are more axially oriented innovations, which collectively offer citywide coverage, in Brighton. 
Secondly, trajectories of path-dependent innovation - and hence transition - are city-specific. The previously discussed developments regarding cycling exemplify one such a trajectory, into which Brighton has gradually become "locked in" due to several interacting processes:

- The positive reinforcement that follows from the perception that earlier initiatives have been successful.

- The emergence of specialized expertise and a (small) workforce of travel planners within BHCC.

- Continued success with raising money from dedicated funding programs run by DfT and the EU. In 2005 Brighton became one of six Cycling Demonstration Towns - national test bed sites allowing governments to learn about what can be achieved in the UK with continental-European level of investment per capita in cycling - and subsequently benefited from the follow-up Cycling Town program (2008-2011) and more recently the LSTF (2011-2016). The city also obtained EU funding (CiviTAS) to bolster its activities.

- The strongly territorialized nature of most cycling-related innovations: partly in response to restrictions imposed by external funders, most travel planning projects and road retrofits have been — and still are-limited to specific neighborhoods in the city, meaning there has been at least until now a supply of areas for retrofit and travel planning.

A similar cycling oriented trajectory cannot be discerned in Oxford. This is partly a consequence of its pre-existing subaltern regime of velomobility yet also reflects a more neoliberal and less interventionist style of governing mobility by local government that has existed for several decades ( $c f$. [76]) but seems to be changing. Since 2012 the city has had the Oxford Cycle City strategy, aiming to make "Oxford ... one of the truly great cycling cities of Europe" [77] in response to initiatives in other UK cities (and the desire not to lag behind) and the buzz around cycling safety across the UK more generally.

Oxford has also witnessed something of an electric mobility trajectory, although this is not nearly as coherent as Brighton's string of cycling-related innovations. The electric mobility trajectory ties different modes and actors together as it comprises not only OBC's substantial investment in HEV buses (see Section 4.3) and the community-led e-car club in North Oxford. Also included are the city's network of charging points and the Mini-E trial ran by BMW and Oxford Brookes University (OBU). As part of the latter, 20 Minis were provided to professional organizations, including Oxford City Council, and to two waves of 20 householders in Oxford (and London) for several weeks, so that drivers could learn about EVs and BMW and OBU could study the cars' performance and dynamics in user practices, perceptions and attitudes. The project has so far not had a follow-up but it did make the city council amenable to procuring several EVs and creating some non-publicly available charging points for its own fleet. Oxford also has a network of commercially operated charging points. At the moment of writing, there are eight locations, against four in Brighton; half are located in various parts of the city, and the other can be found at four of the five P\&R locations that surround the city (one is equipped with rapid charging technology). As before, an important driver behind this electric mobility trajectory is the city's air quality problem and strategy to tackle this. Yet, this is also where a discrepancy can be noticed between city and county council: the former is focused more strongly on air quality, whilst the latter is formally responsible for reducing road congestion; the consequence is a slight ambivalence in support for EV-related innovations in Oxford. 
The third variation concerns funding: a comparison of Tables 2 and 3 reveals greater reliance on supra-local-DfT and EU-funding streams in Brighton than in Oxford. This difference is due to a combination of strategy and differential success rates: over the past decade Brighton's local government has been more proactive in raising external funds to finance its aspirations regarding innovation, and early successes in obtaining grants and the reputational value created by actual delivery on promises seem to have played a role in subsequent awards. However, actors within BHCC also realize that success cannot be taken for granted in the near future. As a consequence of the austerity politics of Cameron's Coalition Government, the annual allocations of DfT funds for transport planning to local authorities will be reduced substantially in the coming years. This will probably mean that competition from other local governments for future funding programs - the successor to LSTF, for instance-will become fiercer, and that less staff capacity within BHCC will be available to prepare future bids.

Oxford may well be a strong competitor in future funding programs. Both city and council governments seem to have become more interventionist in recent years and are now more proactive in attempts to raise external funds from national government and the EU's current funding program Horizon 2020. Moreover, local government is reaching out more actively than before to actors in the

private sector and also to the city's two universities. These more complex arrangements for governing innovations in low-energy mobility are partly a response to funder requirements but also reflect local actors' shared aspiration to become a "smart city". Transport in general and low-energy mobility in particular have been identified as an important domain for experimentation with new (IT-based) technologies, and local government appreciates that the city's universities and IT firms can make critical contributions to the realization of further innovations in electric mobility, intermodal mobility, mobility services and mobility management. These potential innovations - like many of those included in Tables 2 and 3-cannot be considered as being simply or even predominantly local. They transcend administrative boundaries and hierarchically ordered, nested geographical scales (cf. [34]) but without being placeless: they also internalize and embody the historically sedimented specificities of the territory where they become part of existing mobility systems.

\section{Conclusions}

Using a case study approach and informed by the sociotechnical transitions literature, this paper has demonstrated that many innovations contributing to reduced GHG emissions and energy consumption from everyday mobility have been realized recently in Brighton and Oxford. Activity has been particularly pronounced since 2010, focusing on different transport modes - and sometimes at intermodal mobility — and involving many different actors, both incumbent and new. Examples of the latter include start-up companies specializing in low-energy mobility, not-for-profit organizations and collectives, and local universities. It is tempting to conclude that in both cities an innovation-based systemic change toward low-energy mobility futures is underway. Yet, the admittedly very basic statistics in Table 1 also suggest that, at least for commuting, private car use (in internal combustion vehicles) remains by far the most important form of transport. There is still a long way to go toward urban mobility that is genuinely environmentally sustainable.

There is also a clear geography to the innovation patterns characterizing both cities, in a double sense. Place-specific and path-dependent trajectories of innovation in each city can be identified. There is 
considerably greater emphasis on commercial car sharing; cycling oriented retrofitting of road infrastructure; and travel planning focused on residences, workplaces and educational institutions in Brighton. In contrast, there has been greater activity in electric mobility in Oxford, partly because of greater air quality issues and more concerted action from local government on these. The second sense relates to how innovation activity in each city is relational and embedded in wider geographical configurations. In both cities most activity is funded by money that comes from national government sources, but Brighton's local government has so far been more proactive and more successful in raising money from specialized funding programs oriented at cycling and/or sustainable transport run by national government and the EU. This appears to be changing, however, and Oxford has recently become more proactive in obtaining supra-local government funding. Whilst this is to some extent the consequence of wider processes of state restructuring in the UK ( $c f$. [78]), the findings also demonstrate the importance of understanding cities as at once relational and territorial [58] rather than as bounded, sealed-off and independent containers in which innovations unfold.

In fact, the financial arrangements discussed in this paper are one source of vulnerability and uncertainty when it comes to future innovation activity and the continuation of transition trajectories. This is because national and EU funding is to be obtained via competitive bidding processes, the outcomes of which cannot be guaranteed in advance. Whilst this study suggests that success in obtaining grants and project delivery seems to breed success, the consequences of failure in obtaining the next tranche of funding are not insignificant. Not only will particular lines of innovation activity have to be cut short, local governments will also lose staff and hence expertise and human capital. This may reduce the speed of sociotechnical transition as well as the trajectories followed, even if the broader direction of travel towards reducing energy consumption and GHG emissions may remain unaltered. Another vulnerability that has surfaced relates to fluctuations in political support for particular types of innovations. As has been suggested, support from local politicians has been important in driving forward cycling projects and the expansion of car sharing in Brighton and to a lesser extent cycling-related innovations in Oxford. Whilst very important, such support is also precarious: it is tied to electoral cycles and can also shift in-between election periods (for instance, under influence of local media campaigns or the actions of pressure groups). It is beyond this paper to explore the temporalities of political support in both case-study cities; suffice to say that there have been significant fluctuations in Brighton in particular, and that these have at times threatened the survival of specific innovations.

The above reflections on vulnerabilities and cities' situatedness in wider spatial configurations of finance - as well as regulation and expertise - raise another issue. As previously discussed, both Brighton and Oxford are in many ways privileged when it comes to the emergence and flourishing of low-energy innovations in the everyday mobility of people. If low-energy transition trajectories and (future) innovations are already prone to precariousness, vulnerability and uncertainty in those cities, what can be expected for others where conditions are less favorable? This question obviously demands empirical scrutiny but, as far as the pace of transition processes is concerned, the findings for Brighton and Oxford do not bode particularly well for smaller and medium-sized cities (up to $\pm 0.5 \mathrm{M}$ inhabitants) at the heart of urban areas with much weaker bus- and velomobility systems in terms of physical infrastructure, regulation, formal expertise, financial resources, cultural values and user practices. It would appear, then, that cities have a significant role to play in reducing GHG emissions and energy consumption in transport in advanced liberal democracies like the UK but expectations about what they 
can achieve should be realistic. By no means should cities be heralded as actors who can bring about significant change semi-autonomously. This is to deny both the social, political, cultural, technological and other struggles that characterize cities, and the critically important role that national and supranational (EU) level actors play in shaping their innovation and low-energy transition trajectories.

\section{Acknowledgments}

The research described in this paper has been supported by the Centre on Innovation and Energy Demand (www.cied.ac.uk), funded by the EPSCR/ESCR (grant number EP/KO11790/1). The comments of three anonymous reviewers on an earlier version of the paper are gratefully acknowledged.

\section{Conflicts of Interest}

The author declares no conflict of interest.

\section{References}

1. Banister, D. Unsustainable Transport: City Transport in the New Century, 1st ed.; Routledge: Abingdon, UK, 2005.

2. Chapman, L. Transport and climate change: A review. J. Transp. Geogr. 2007, 15, 354-367.

3. Banister, D.; Anderton, K.; Bonilla, D.; Givoni, M.; Schwanen, T. Transportation and the environment. Annu. Rev. Environ. Resour. 2011, 36, 247-270.

4. Sims, R.; Schaeffer, R.; Creutzig, F.; Cruz-Núñez, X.; D’Agosto, M.; Dimitriu, D.; Figueroa Meza, M.J.; Fulton, L.; Kobayashi, S.; Lah, O.; et al. Transport. In Climate Change 2014: Mitigation of Climate Change. Contribution of Working Group III to the Fifth Assessment Report of the Intergovernmental Panel on Climate Change, 1st ed.; Edenhofer, O., Pichs-Madruga, R., Sokona, Y., Farahani, E., Kadner, S., Seyboth, K., Adler, A., Baum, I., Brunner, S., Eickemeier, P., et al. Eds.; Cambridge University Press: Cambridge, UK, 2014; pp. 599-670.

5. International Energy Agency. World Energy Outlook 2012, 1st ed.; International Energy Agency: Paris, France, 2012.

6. International Energy Agency. $\mathrm{CO}_{2}$ Emissions from Fuel Combustion: Highlights; International Energy Agency: Paris, France, 2013.

7. Urry, J. Climate Change \& Society, 1st ed.; Polity Press: Cambridge, UK, 2011.

8. Millard-Ball, A.; Schipper, L. Are we reaching peak travel? Trends in passenger transport in eight industrialized countries. Transp. Rev. 2011, 31, 357-378.

9. Newman, P.; Kenworthy, J. 'Peak car use': Understanding the demise of automobile dependence. World Transp. Policy Pract. 2011, 17, 31-42.

10. Babalik-Sutcliffe, E. Urban rail systems: Analysis of the factors behind success. Transp. Rev. 2002, 22, 415-447.

11. Lane, B. Significant characteristics of the urban rail renaissance in the United States: A discriminant analysis. Transp. Res. Part A 2008, 42, 279-295.

12. Garmendia, M.; Ribalaygua, C.; Ureña, J.M. High speed rail: Implication for cities. Cities 2012 , 29(Suppl. 2), S26-S31. 
13. Buehler, R.; Pucher, J. City Cycling, 1st ed.; MIT Press: Cambridge, MA, USA, 2012.

14. Lanzendorf, M.; Busch-Geertsema, A. The cycling boom in large German cities-empirical evidence for successful cycling campaigns. Transp. Policy 2014, 36, 26-33.

15. Newman, P.; Kenworthy, J. Sustainability and Cities: Overcoming Automobile Dependence, 1st ed.; Island Press: Washington, DC, USA, 1999.

16. Banister, D. Cities, mobility and climate change. J. Transp. Geogr. 2011, 19, 1538-1546.

17. Castán Broto, V.; Bulkeley, H. A survey of urban climate change experiments in 100 cities. Glob. Environ. Chang. 2013, 23, 92-102.

18. Geels, F.W. From sectoral systems of innovation to socio-technical systems: Insights about dynamics and change from sociology and institutional theory. Res. Policy 2004, 33, 897-920.

19. Nykvist, B.; Whitmarsh, L. A multi-level analysis of sustainable mobility transitions: Niche development in the UK and Sweden. Technol. Forecast. Soc. Chang. 2008, 75, 1373-1387.

20. Geels, F.W. A socio-technical analysis of low-carbon transitions: Introducing the multi-level perspective into transport studies. J. Transp. Geogr. 2011, 24, 445-467.

21. Kemp, R.; Schot, J.; Hoogma, R. Regime shifts to sustainability through processes of niche formation: The approach of strategic niche management. Technol. Anal. Strateg. Manag. 1998, 10, 175-195.

22. Schot, J.; Geels, F.W. Strategic niche management and sustainable innovation journeys: Theory, findings, research agenda, and policy. Technol. Anal. Strateg. Manag. 2008, 20, 537-554.

23. Smith, A.; Raven, R. What is protective space? Reconsidering niches in transitions to sustainability. Res. Policy 2012, 41, 1025-1036.

24. Rip, A.; Kemp, R. Technological change. In Human Change and Climate Change-Resources and Technology 2, 1st ed.; Rayner, S., Malone, E.L., Eds.; Batelle: Columbus, OH, USA, 1998; pp. 327-399.

25. Geels, F.W. Technological transitions as evolutionary reconfiguration processes: A multi-level perspective and case-study. Res. Policy 2002, 31, 1257-1274.

26. Shove, E.; Walker, G. Governing transitions in the sustainability of everyday life. Res. Policy 2010, 39, 471-476.

27. Watson, M. How theories of practices can inform transition to a decarbonised transport system. J. Transp. Geogr. 2014, 24, 488-496.

28. Aldred, R.; Jungnickel, K. Why culture matters for transport policy: The case of cycling in the UK. J. Transp. Geogr. 2014, 34, 78-87.

29. Hopkins, D.; Stephenson, S. Generation Y mobilities through the lens of energy cultures: A preliminary exploration of mobility cultures. J. Transp. Geogr. 2014, 38, 88-91.

30. Stephenson, J.; Hopkins, D.; Doering, A. Conceptualising transport transitions: Energy Cultures as an organising framework. Wiley Interdiscip. Rev. Energy Environ. 2015, doi:10.1002/wene.129.

31. Hodson, M.; Marvin, S. Cities mediating technological transitions: Understanding vision, intermediation and consequences. Technol. Anal. Strateg. Manag. 2009, 21, 515-534.

32. Coenen, L.; Raven, R.; Verbong, G. Local niche experimentation in energy transitions: A theoretical and empirical exploration of proximity advantages and disadvantages. Technol. Soc. 2010, 32, 295-302.

33. Coenen, L.; Benneworth, P.; Truffer, B. Toward a spatial perspective on sustainability transitions. Res. Policy 2012, 41, 968-979. 
34. Raven, R.; Schot, J.; Berkhout, F. Space and scale in socio-technical transitions. Environ. Innov. Soc. Transit. 2012, 4, 63-78.

35. Bulkeley, H.; Castán Broto, V. Government by experiment? Global cities and the governing of climate change. Trans. Inst. Br. Geogr. 2013, 38, 361-375.

36. McCormick, K.; Anderberg, S.; Coenen, L.; Neij, L. Advancing sustainable urban transformation. J. Clean. Prod. 2013, 50, 1-11.

37. Longhurst, N. Towards and 'alternative' geography of innovation: Alternative milieu, socio-cognitive protection and sustainability experimentation. Environ. Innov. Soc. Innov. 2015, in press.

38. Murphy, J.T. Human geography and socio-technical transition studies: Promising intersections. Environ. Innov. Soc. Innov. 2015, in press.

39. Sengers, F.; Raven, R. Toward a spatial perspective on niche development: The case of Bus Rapid Transit. Environ. Innov. Soc. Innov. 2015, in press.

40. Flyvbjerg, B. Case study. In The Sage Handbook of Qualitative Research, 4th ed.; Denzin, N.K., Lincoln, Y.S., Eds.; Sage: Thousand Oaks, CA, USA, 2011; pp. 301-316.

41. Department for Transport. Local Sustainable Transport Fund. Available online: https://www.gov.uk/ government/collections/local-sustainable-transport-fund (accessed on 30 March 2015).

42. Unruh, G.C. Escaping carbon lock-in. Energy Policy 2002, 30, 317-325.

43. Bakker, S.; Maat, K.; van Wee, B. Stakeholders interests, expectations, and strategies regarding the development and implementation of electric vehicles: The case of the Netherlands. Transp. Res. Part A 2014, 66, 54-64.

44. Geels, F.W. The multi-level perspective on sustainability transitions: Responses to seven criticisms. Environ. Innov. Soc. Transit. 2011, 1, 24-40.

45. McDowell, L. Work, workfare, work/life balance and an ethic of care. Progr. Hum. Geogr. 2004, 28, 145-163.

46. Geels, F.W.; Kemp, R.; Dudley, G.; Lyons, G. Automobility in Transition? A Socio-technical Analysis of Sustainable Transport, 1st ed.; Routledge: New York, NY, USA, 2012.

47. Sengers, F.; Raven, R. Metering motorbike mobility: Informal transport in transition? Technol. Anal. Strateg. Manag. 2014, 26, 453-468.

48. Van Bree, B.; Verbong, G.P.J.; Kramer, G.J. A multi-level perspective on the introduction of hydrogen and battery-electric vehicles. Technol. Forecast. Soc. Chang. 2010, 77, 529-540.

49. Bakker, S.; Farla, J. Electrification of the car-Will the momentum last?: Introduction to the special issue. Environ. Innov. Soc. Innov. 2015, 14, 1-4.

50. Raven, R.; Verbong, G. Multi-regime interactions in the Dutch energy sector: The case of combined heat and power technologies in the Netherlands 1970-2000. Technol. Anal. Strateg. Manag. 2007, 19, 491-507.

51. Seyfang, G.; Smith, A. Grassroots innovations for sustainable development: Towards a new research and policy agenda. Environ. Polit. 2007, 16, 584-603.

52. Smith, A.; Seyfang, G. Constructing grassroots innovations for sustainability. Glob. Environ. Chang. 2013, 23, 827-829.

53. Ornetzeder, M.; Rohracher, H. Of solar collectors, wind power, and car sharing: Comparing and understanding successful cases of grassroots innovations. Glob. Environ. Chang. 2013, 23, 856-857. 
54. Perren, L.; Sapsed, J. Innovation as politics: The rise and reshaping of innovation in UK parliamentary discourse 1960-2005. Res. Policy 2013, 42, 1815-1828.

55. Upham, P.; Kivimaa, P.; Mickwitz, P.; Åstrand, K. Climate policy innovation: A sociotechnical transitions perspective. Environ. Polit. 2014, 23, 774-794.

56. Boyatzis, R.E. Transforming Qualitative Information: Thematic Analysis and Code Development, 1st ed.; Sage: Thousand Oaks, CA, USA, 1998.

57. Ward, K. Towards a relational comparative approach to the study of cities. Progr. Hum. Geogr. 2010, 34, 471-487.

58. McCann, E.; Ward, K. Relationality/territoriality: Toward a conceptualization of cities in the world. Geoforum 2010, 41, 175-184.

59. Massey, D. For Space, 1st ed.; Sage: London, UK, 2004.

60. Bertilsson, T.M. The elementary forms of pragmatism: On different types of abduction. Eur. J. Soc. Theory 2004, 7, 371-389.

61. Lucas, K.; Jones, P. The Car in British Society, 1st ed.; RAC Foundation: London, UK, 2009.

62. Office for National Statistics. 2011 Census Analysis, Method of Travel to Work in England and Wales. Available online: http://www.ons.gov.uk/ons/publications/re-reference-tables.html?edition= tcm\%3A77-295663 (accessed on 30 March 2015).

63. Office for National Statistics. Cycling to Work. Available online: http://www.ons.gov.uk/ons/ publications/re-reference-tables.html?edition=tcm\%3A77-295663 (accessed on 30 March 2015).

64. Flyvbjerg, B.; Skamris Holm, M.; Buhl, S. Underestimating costs in public works projects: Error or lie? J. Am. Plan. Assoc. 2002, 68, 279-295.

65. Flyvbjerg, B. Cost overruns and demand shortfalls in urban Rail and Other Infrastructure. Transp. Plan. Technol. 2007, 30, 9-30.

66. Ormrod, R.K. Local context and innovation diffusion in a well-connected world. Econ. Geogr. 1990, 66, 109-122.

67. Ormrod, R.K. Adaptation and cultural diffusion. J. Geogr. 1992, 91, 258-262.

68. McCann, E. Urban policy mobilities and global circuits of knowledge: Toward a research agenda. Ann. Assoc. Am. Geogr. 2011, 101, 107-130.

69. Peck, J. Geographies of policy: From transfer-diffusion to mobility-mutation. Progr. Hum. Geogr. 2011, 35, 773-797.

70. McCann, E.; Ward, K. Mobile Urbanism: Cities and Policymaking in the Global Age, 1st ed.; The University of Minnesota Press: Minneapolis, MN, USA, 2012.

71. Raven, R. Niche accumulation and hybridisation strategies in transition processes towards a sustainable energy system: An assessment of differences and pitfalls. Energy Policy 2007, 35, 2390-2400.

72. Shaw, J.; MacKinnon, D.; Docherty, I. Divergence or convergence? Devolution and transport policy in the United Kingdom. Environ. Plan. C 2009, 27, 546-567.

73. Oxford Bus Company. Annual Corporate and Social Responsibility Report 2014; Oxford Bus Company: Oxford, UK. Available online: http://assets.goaheadbus.com/media/cms_page_media/ 70/CSR\%20Report\%20WEB.pdf (accessed on 28 March 2014).

74. Enoch, M. Sustainable Transport, Mobility Management and Travel Plans, 1st ed.; Ashgate: Aldershot, UK, 2012. 
75. Sebastian Bamberg, S.; Fujii, S.; Friman, M.; Gärling, T. Behaviour theory and soft transport policy measures. Transp. Policy 2011, 18, 228-235.

76. Lawton Smith, H. Local innovation assemblages and institutional capacity in local high-tech economic development: The case of Oxfordshire. Urban Stud. 2003, 40, 1353-1369.

77. City of Oxford, Cycling and Walking. Available online: http://www.oxford.gov.uk/PageRender/ decTS/Cycling_and_Walking_occw.htm (accessed on 13 May 2015).

78. MacKinnon, D.; Shaw, J. New state spaces, agency and scale: Devolution and the regionalisation of transport governance in Scotland. Antipode 2011, 42, 1226-1252.

(C) 2015 by the author; licensee MDPI, Basel, Switzerland. This article is an open access article distributed under the terms and conditions of the Creative Commons Attribution license (http://creativecommons.org/licenses/by/4.0/). 